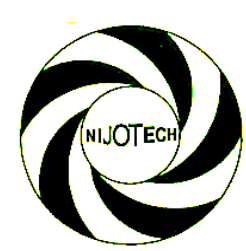

Nigerian Journal of Technology (NIJOTECH)

Vol. 37, No. 1, January 2018, pp. 60 - 66

Copyright@ Faculty of Engineering, University of Nigeria, Nsukka

Print ISSN: 0331-8443, Electronic ISSN: 2467-8821

www.nijotech.com

http://dx.doi.org/10.4314/njt.v37i1.8

\title{
A MODEL FOR THE DETERMINATION OF THE CRITICAL BUCKLING LOAD OF SELF-SUPPORTING LATTICE TOWERS
}

\author{
M. E. Onyia ${ }^{1, *}$ and M. C. Nwosu ${ }^{2}$ \\ 1, 2 Department of Civil EngineEring, University of Nigeria, NSUKKA. EnUGU STATE, NiGERIA. \\ Email addresses:1 michael.onyia@unn.edu.ng,2michael_co_nwosu@yahoo.com
}

\begin{abstract}
Most tall columns under axial load fail by buckling. Considering the widespread use of this type of structure and the critical role it plays in service delivery, its failure will result in possible loss of lives and property and disruption of services. It is therefore necessary to evolve alternative methods of determination of the buckling load of selfsupporting lattice towers. This paper therefore proposes a simple model for the determination of the critical buckling load of self- supporting lattice towers. The proposed model idealizes the lattice tower as an equivalent solid beamcolumn whose cross-sectional-dimensions are the unknowns to be determined. The expression $P_{c r}=\frac{\pi^{2} b^{4} E}{48 h^{2}}$ is proposed by the model for the critical buckling load of self-supporting lattice tower, whose equivalent solid beamcolumn has a dimension $b$ at its free end. The results obtained using the proposed model are shown to be acceptable, with a percentage difference of about $0.036 \%$ when compared with results obtained using conventional methods.
\end{abstract}

Keywords: Lattice Tower, Beam-column, Buckling load, Truss.

\section{INTRODUCTION}

Towers are tall steel frame structures used for different purposes such as installation of equipment for telecommunication, radio transmission, satellite reception, power transmission, air traffic control, television transmission, flood lights, meteorological measurements, etc. Lattice towers act as cantilever trusses since they are usually clamped at the base. They resist wind and seismic loads, as well as vertical load from self-weight and equipment installed on the tower, [1].

Lattice towers can be analysed as vertical trusses which resist wind load by cantilever action, [2]. Towers are subjected to both vertical and horizontal forces, the significant horizontal forces being as a result of wind action on the vertical part of the tower, [3]. A column buckling analysis consists of determining the maximum load a column can support before it collapses. The critical load is the greatest load that will not cause lateral deflection (buckling) of the column. For loads greater than the critical load, the column will deflect laterally. The critical load puts the column in a state of unstable equilibrium, $[4,16]$. A load beyond the critical will cause the column to fail by buckling. For long columns, failure by buckling has nothing to do with material yield. It is instead governed by the column's stiffness, both material and geometric, $[5,6]$.

This paper proposes a model for the determination of the critical buckling load of self-supporting lattice towers by replacing the actual tower with an equivalent beam-column.

\section{STRUCTURAL MODELLING}

The structural model is a solid beam-column of exactly the same height and lateral deflection curve as the actual self-supporting lattice tower. The cross sections of both the self-supporting tower and the equivalent structure should be similar but must not be equal in dimensions. (Figure 1).

Since the self-supporting truss tower is normally prevented from movement at its base, the equivalent solid beam-column is analysed as a linearly-varying cantilever beam, [7]. The equivalent beam-column is assumed to have the same values of lateral deflection (sway) under the action of the same applied loads at exactly the same points along its length as the selfsupporting lattice tower, $[8,9,10]$. The analysis thus considers the failure of the tower structure as a whole, rather than the failure of the individual truss members. 


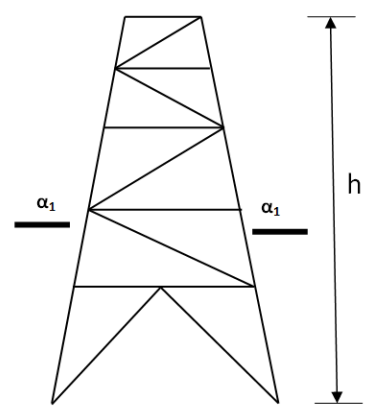

a) Self-supporting lattice tower

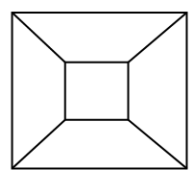

Section $a_{1}-a_{1}$

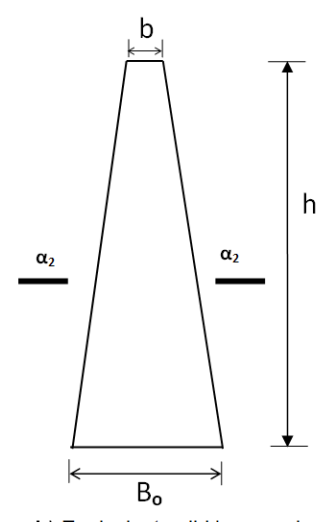

b) Equivalent solid beam-column

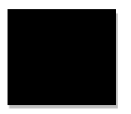

Section $a_{2}-a_{2}$

Figure 1: Structural modelling of lattice tower

\section{MATHEMATICAL MODELLING}

The analysis consists of the following steps

(i) an appropriate structural model (equivalent solid beam-column) that best suits the actual structure (self-supporting lattice tower) under consideration was selected. The model must have exactly the same height and cross-sectional shape as the actual structure.

(ii) an analysis of the actual self-supporting lattice tower with the given dimensions and loadings was performed to determine the numerical values of lateral deflection (sway) along its length.

(iii) using the determined deflection values at known points on the actual structure, the unknown crosssectional dimensions of the equivalent solid beam-column were determined by equating deflections at the same points along the length of the equivalent structure. Thus, the self-supporting lattice tower and the equivalent solid beamcolumn have to be analyzed under the action of the same loadings acting at the same points and direction.

(iv) a dynamic analysis of the equivalent solid beamcolumn was performed to determine its natural vibration frequencies.

\subsection{Cross-Sectional Properties of the Equivalent Solid Beam-Column}

Consider a solid beam-column structure of height $h$ with a linearly-tapering cross-section and fixed at its base, (Fig. 2).

A horizontal force $\mathrm{P}$ is applied at its free end. The bending moment along the cantilever solid beam is
$M_{x}=P .(h-x)$

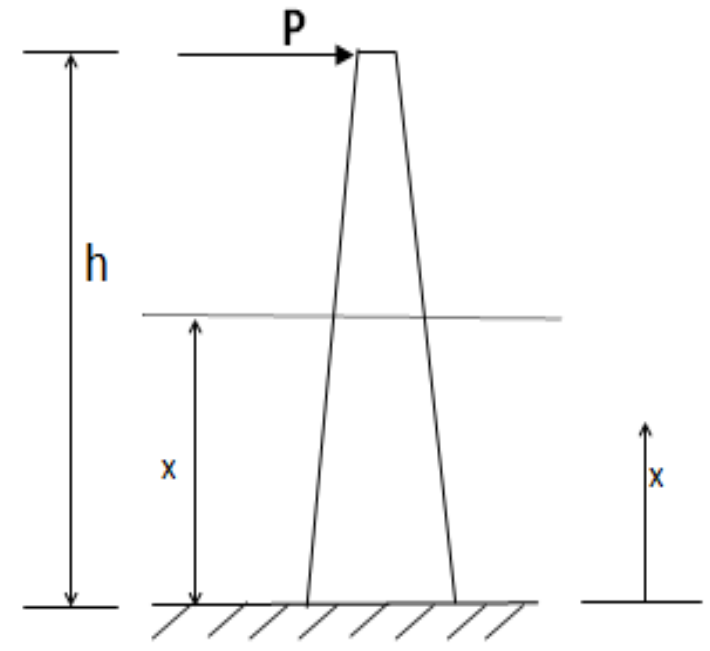

Figure 2: Solid beam-column with linearly-tapering cross-section

From theory of structures, strain energy due to the applied load is, [11]:

$$
\mathrm{UB}=\int \frac{\mathrm{M}_{\mathrm{x}}^{2} \mathrm{dx}}{2 \mathrm{EI}_{\mathrm{x}}}
$$

From Castigliano's theorem, the deflection of the member is expressed as, [11]:

$$
\delta_{\mathrm{B}}=\frac{\partial \mathrm{U}_{\mathrm{B}}}{\partial \mathrm{P}}=\int \frac{\mathrm{M}_{\mathrm{x}}}{\mathrm{EI}_{\mathrm{x}}} \frac{\partial \mathrm{M}_{\mathrm{x}}}{\partial \mathrm{P}} \mathrm{dx}
$$

The linearly-tapering dimension of the beam-column can be expressed as, $[7,12]$ :

$$
\mathrm{B}_{\mathrm{x}}=\mathrm{a} .+\mathrm{cx}
$$

where $B_{X}$ is the width of the cross-section at any point $x$ along the length of the equivalent beam-column structure (Fig.3). 

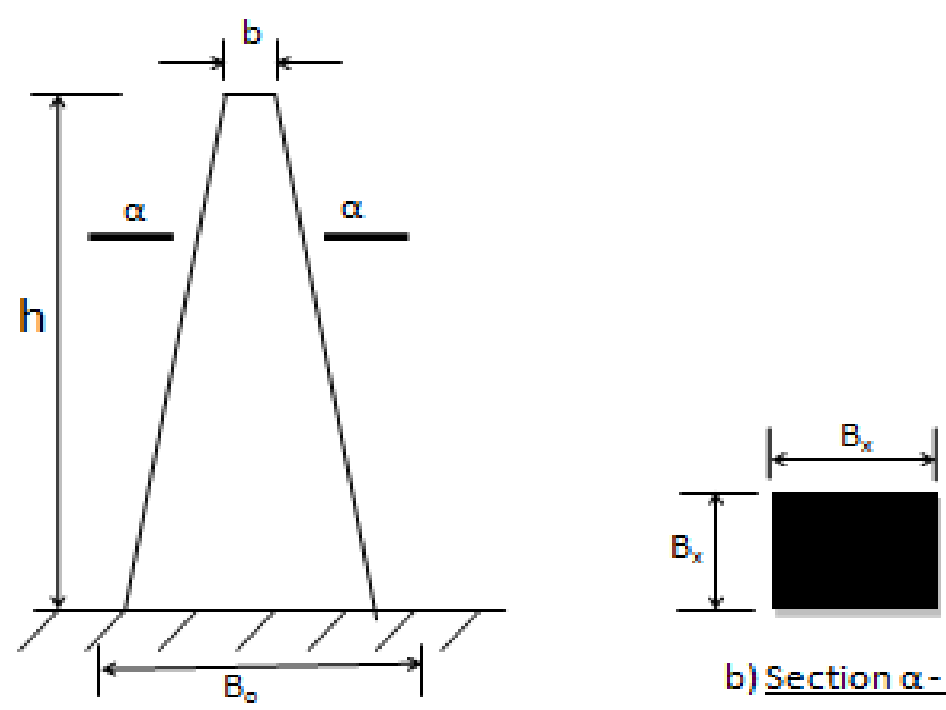

b) $\underline{\operatorname{section} \alpha-\alpha}$

\section{a) Solid beam-column}

Figure 3: Cross-sectional dimensions of the equivalent beam-column

To determine the values of the constants a and $\mathrm{c}$ in Equation (4), we need to consider the boundary conditions of the equivalent beam-column structure under consideration, (Fig.3):

(i) At $x=0$ (base), $B_{x}=B_{0}$

(ii) At $x=h$ (top), $B_{x}=b$

$$
\therefore \quad \mathrm{B}_{\mathrm{x}}=\frac{\mathrm{B}_{0} \mathrm{~h}+\left(\mathrm{b}-\mathrm{B}_{0}\right) \mathrm{x}}{\mathrm{h}}
$$

The moment of inertia for the equivalent solid beam can be expressed in terms of $\mathrm{B}_{\mathrm{X}}$.

Moment of Inertia, $I_{x}=\frac{B_{x}\left(B_{x}\right)^{3}}{12}$ i.e.

$$
\mathrm{I}_{\mathrm{x}}=\frac{\left[\mathrm{B}_{\mathrm{o}} \mathrm{h}+\left(\mathrm{b}-\mathrm{B}_{\mathrm{o}}\right) \mathrm{x}\right]^{4}}{12 \mathrm{~h}^{4}}
$$

Putting $\mathrm{B}_{\mathrm{o}} \mathrm{h}=\alpha_{\mathrm{o}}$ and $\mathrm{b}-\mathrm{B}_{\mathrm{o}}=\beta$

Then the expressions for $B_{x}$ and $I_{x}$ can be expressed as follows:

$$
\begin{aligned}
& B x=\frac{\alpha_{0}+\beta \mathrm{x}}{\mathrm{h}} \\
& \mathrm{I}_{\mathrm{x}}=\frac{\left(\alpha_{0}+\beta \mathrm{x}\right)^{4}}{12 \mathrm{~h}^{4}}
\end{aligned}
$$

The strain energy of the equivalent structure is given by Equation (2). Substituting for $\mathrm{M}_{\mathrm{x}}$ and $\mathrm{I}_{\mathrm{x}}$ in the strain energy equation gives:

$$
U_{B}=(x)=\frac{6 P^{2} h^{4}}{E} \int \frac{(h-x)^{2}}{\left(\alpha_{0}+\beta x\right)^{4}} d x
$$

From Castigliano's theorem, the deflection of the equivalent structure is given by Equation (3). But $M_{x}=$

$$
\begin{gathered}
\mathrm{P}(\mathrm{h}-\mathrm{x}) \text { and } \mathrm{I}_{\mathrm{x}}=\frac{\left(\alpha_{0}+\beta \mathrm{x}\right)^{4}}{12 \mathrm{~h}^{4}} \text {. Thus, } \frac{\partial \mathrm{M}_{\mathrm{x}}}{\partial \mathrm{P}}=\mathrm{h}-\mathrm{x} \\
\therefore \mathrm{Y}_{\mathrm{E}}(\mathrm{x})=\int \frac{\mathrm{M}_{\mathrm{x}}}{\mathrm{EI}_{\mathrm{x}}}\left(\frac{\partial \mathrm{M}_{\mathrm{x}}}{\partial \mathrm{P}}\right) \mathrm{dx} \\
\text { i. e. } Y_{e}=\frac{12 \mathrm{~h}^{4} \mathrm{P}}{\mathrm{E}} \int \frac{(\mathrm{h}-\mathrm{x})^{2}}{\left(\alpha_{0}+\beta \mathrm{x}\right)^{4}} \mathrm{dx}
\end{gathered}
$$

Integrating Equation (10) by partial fractions, we get equation (11)

$$
\begin{aligned}
Y_{E}(x)=\left(\frac{-12 h^{4} P}{E \beta^{3}}\right) & \cdot\left[\frac{1}{\left(\alpha_{0}+\beta x\right)}-\frac{\left(\alpha_{0}+\beta h\right)}{\left(\alpha_{0}+\beta x\right)^{2}}\right. \\
& +\frac{\left(\alpha_{0}+\beta h\right)^{2}}{3\left(\alpha_{0}+\beta x\right)^{3}}-\frac{1}{\alpha_{0}}+\frac{\left(\alpha_{0}+\beta h\right)}{\alpha_{0}{ }^{2}} \\
& \left.-\frac{\left(\alpha_{0}+\beta h\right)^{2}}{3 \alpha_{0}{ }^{3}}\right]
\end{aligned}
$$

In (11) $\alpha_{\mathrm{o}}=\mathrm{B}_{0} \mathrm{~h}$ and $\beta=\mathrm{b}-\mathrm{B}_{0}$. The proposed model (i.e. the beam-column) can only be said to be equivalent to the actual self-supporting lattice tower if its deflection curve under the action of the same loading is the same as that of the actual tower, $[9,13]$. Therefore, the self-supporting lattice tower should be analyzed statically for deflection along its length and the values at $x=h$ and $x=\frac{h}{2}$ equated to the above expression for deflection of the equivalent solid beamcolumn (i.e Equation 11) to determine the unknown values of its cross-section, $b$ and $B_{0}$. If the deflection of the free end (tip) is $Y$, then putting $\mathrm{x}=\mathrm{h}$ in (11), and noting that $\alpha_{o}=B_{0} h$ and $\beta=b-B_{0}$, we get $Y_{1}=\frac{4 h^{3} P}{E b B_{o}{ }^{3}}$.

$$
\begin{gathered}
b=\frac{C}{Y_{1} B_{0}{ }^{3}} \\
\text { where } c=\frac{4 h^{3} \mathrm{P}}{E}
\end{gathered}
$$

If the deflection at the middle is $\mathrm{Y}_{1 / 2}$, then putting $\mathrm{x}=\frac{\mathrm{h}}{2}$ in Equation (11), we have that:

$$
\alpha_{1} B_{0}{ }^{12}+\alpha_{2} B_{0}{ }^{8}+\alpha_{3} B_{0}{ }^{4}+\alpha_{4}=0
$$
where, 


$$
\begin{aligned}
\alpha_{1}=\mathrm{Y}_{1}{ }^{3} \mathrm{Y}_{\frac{1}{2}}, \alpha_{2}= & \mathrm{CY}_{1}^{2}\left(\mathrm{Y}_{\frac{1}{2}}-3 \mathrm{Y}_{1}\right), \alpha_{3} \\
& =3 \mathrm{C}^{2} \mathrm{Y}_{1}\left(\mathrm{Y}_{\frac{1}{2}}-\mathrm{Y}_{1}\right), \alpha_{4} \\
& =\mathrm{C}\left(\mathrm{Y}_{\frac{1}{2}}-\mathrm{C}^{2} \mathrm{Y}_{1}\right)
\end{aligned}
$$

The values of $\mathrm{b}$ and $B_{0}$ are then determined from Equations (12) and (14).

\subsection{Beam-Column Differential Equation}

In considering the elastic buckling load of a column, it is necessary to determine the load at which the structure remains in equilibrium in the deformed position. In order to derive the necessary equations, consider an element of a beam-column in the deformed position with the forces acting as shown in Fig.4. It is assumed that during the deformation, the axial load remains in its original direction.

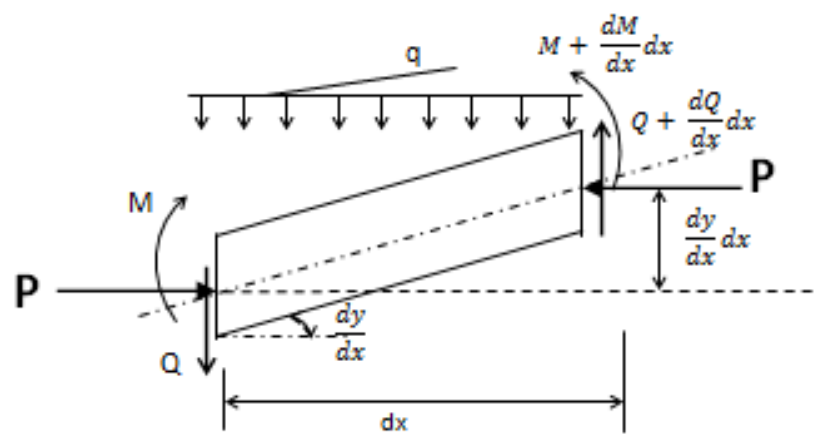

Figure 4: Forces acting on a beam-column in the deformed state

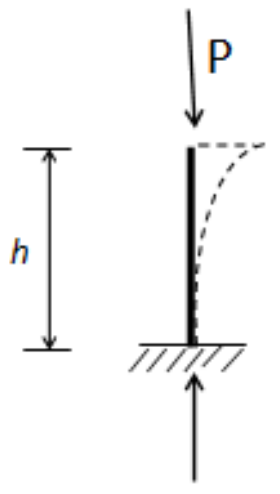

Figure 5: Mode of buckling of a Cantilever beamcolumn

From vertical equilibrium considerations,

$$
\begin{gathered}
\left(\mathrm{Q}+\frac{\mathrm{dQ}}{\mathrm{dx}} \mathrm{dx}\right)-\mathrm{qdx}-\mathrm{Q}=0 \\
\text { or } \frac{\mathrm{dQ}}{\mathrm{dx}}=\mathrm{q}
\end{gathered}
$$

Taking moments,

$$
\begin{gathered}
\left(M+\frac{d M}{d x} d x\right)-M+\left(Q+\frac{d Q}{d x} d x\right) d x+P\left(\frac{d y}{d x} d x\right) \\
-q d x \cdot \frac{d x}{2}=0
\end{gathered}
$$

Ignoring second-order terms,

$$
\begin{array}{r}
\frac{\mathrm{dM}}{\mathrm{dx}}+\mathrm{Q}+\mathrm{P} \frac{\mathrm{dy}}{\mathrm{dx}}=0 \\
\text { i.e. } \mathrm{Q}=-\frac{\mathrm{dM}}{\mathrm{dx}}-\mathrm{P} \frac{\mathrm{dy}}{\mathrm{dx}}
\end{array}
$$

Differentiating Equation (17) with respect to $\mathrm{x}$ :

$\frac{d Q}{d x}=-\frac{d^{2} M}{d x^{2}}-P \frac{d^{2} y}{d x^{2}}$

But from Equation (16), $\frac{d Q}{d x}=q$

$-\left(\frac{\mathrm{d}^{2} \mathrm{M}}{\mathrm{dx}^{2}}+\mathrm{P} \frac{\mathrm{d}^{2} \mathrm{y}}{\mathrm{dx}^{2}}\right)=\mathrm{q}$

But $\quad M=\frac{\operatorname{EId}^{2} \mathrm{y}}{\mathrm{dx}^{2}}$

Thus, $\quad \frac{\mathrm{d}^{2}}{\mathrm{dx}^{2}}\left(\mathrm{EI} \frac{\mathrm{d}^{2} \mathrm{y}}{\mathrm{dx}^{2}}\right)+\mathrm{P} \frac{\mathrm{d}^{2} \mathrm{y}}{\mathrm{dx}^{2}}=-\mathrm{q}$

If it is assumed that EI is constant, then Equation (18) can be written as:

$$
E I \frac{d^{4} y}{d x^{4}}+P \frac{d^{2} y}{d x^{2}}=-q
$$

This equation is generally known as the beam-column equation. Note that in a beam-column equation, shear force $Q$ is given by Equation (17) as:

$$
Q=-\frac{d M}{d x}-\frac{P d y}{d x}=-\left(E I \frac{d^{3} y}{d x^{3}}+P \frac{d y}{d x}\right)
$$

The solution to the beam-column equation,(Equation 19), which is a fourth-order ordinary differential equation with constant coefficients, is given by:

$$
\begin{array}{r}
\mathrm{y}=\mathrm{A} \operatorname{Cos} \alpha \mathrm{x}+\mathrm{B} \operatorname{Sin} \alpha \mathrm{x}+\mathrm{C} \alpha \mathrm{x}+\mathrm{D} \\
+ \text { Particular Integral }
\end{array}
$$

where $\alpha^{2}=\frac{P}{E I}$ and $A$ to $D$ are constants of integration. Once the value of $\mathrm{q}$ is known, then the particular integral can be determined.

\subsection{Buckling Load of Equivalent Beam-Column}

From Equation (21):

$$
\begin{aligned}
y=A \operatorname{Cos} \alpha x+ & B \operatorname{Sin} \alpha x+C \alpha x+D, M=\frac{\operatorname{EId}^{2} y}{{d x^{2}}^{2}} \\
\therefore M & =E I \alpha^{2}(-A \operatorname{Cos} \alpha x-B \operatorname{Sin} \alpha x)
\end{aligned}
$$

From Equation (20), $Q=\frac{-d M}{d x}-P \frac{d y}{d x}$

$$
\text { i. e. } \begin{aligned}
& Q=-\frac{d}{d x}\left(\frac{E I d^{2} y}{d x^{2}}\right)-P \frac{d y}{d x} \\
& \text { But } \quad \alpha^{2}=\frac{P}{E I}
\end{aligned}
$$$$
\therefore \mathrm{P}=\mathrm{EI} \alpha^{2}
$$

$$
\begin{gathered}
\text { Thus, } \quad Q=-\left[E I \frac{d^{3} y}{d^{3}}+E^{2} \alpha^{2} \frac{d y}{d x}\right] \\
\text { or } \quad Q=-E I\left(\frac{d^{3} y}{d x^{3}}+\frac{\alpha^{2} d y}{d x}\right)
\end{gathered}
$$


Substituting for $\frac{d^{3} y}{d x^{3}}$ and $\frac{d y}{d x}$

$$
\begin{gathered}
\mathrm{Q}=-\mathrm{EI}\left(\mathrm{A} \operatorname{Sin} \alpha \mathrm{x}-\alpha^{3} \mathrm{~B} \operatorname{Cos} \alpha \mathrm{x}-\alpha^{3} \mathrm{~A} \operatorname{Sin} \alpha \mathrm{x}\right. \\
\left.+\alpha^{3} \mathrm{~B} \operatorname{Cos} \alpha \mathrm{x}+\alpha^{3} \mathrm{C}\right) \\
\therefore \mathrm{Q}=-\mathrm{EI} \alpha^{3} \mathrm{C}
\end{gathered}
$$

Note that there are four constants of integration to be determined. This requires four boundary conditions.

For the cantilever beam-column, the boundary conditions are:

(i) Fixed end (base): $y_{x=0}=0$ and $\left(\frac{d y}{d x}\right)_{x=0}=0$

(ii) Free end (top): $\mathrm{M}_{\mathrm{x}=\mathrm{h}}=0$ and $\mathrm{Q}_{\mathrm{x}=\mathrm{h}}=0$

$\mathrm{y}=\mathrm{A} \operatorname{Cos} \alpha \mathrm{x}+\mathrm{B} \operatorname{Sin} \alpha \mathrm{x}+\mathrm{C} \alpha \mathrm{x}+\mathrm{D}$

$\mathrm{y}_{\mathrm{x}=0}=\mathrm{A} \operatorname{Cos} 0+\mathrm{B} \operatorname{Sin} 0+0+\mathrm{D}=0$

$\mathrm{A}+\mathrm{D}=0$ or $\mathrm{D}=-\mathrm{A}$

$\frac{d y}{d x}=-\alpha A \operatorname{Sin} \alpha x+\alpha B \operatorname{Cos} \alpha x+C \alpha$

$\left(\frac{d y}{d x}\right)_{x=0}=-\alpha A \operatorname{Sin} 0+\alpha B \operatorname{Cos} 0+C \alpha=0$

Hence, $\alpha \mathrm{B}+\mathrm{C} \alpha=0$ or $\mathrm{C}=-\mathrm{B}$

$\mathrm{M}=\mathrm{EI} \alpha^{2}(-\mathrm{A} \operatorname{Cos} \alpha \mathrm{x}-\mathrm{B} \operatorname{Sin} \alpha \mathrm{x})$

$\mathrm{M}_{\mathrm{x}=\mathrm{h}}=0, \therefore \mathrm{EI} \alpha^{2}(-\mathrm{A} \operatorname{Cos} \alpha \mathrm{h}-\mathrm{B} \operatorname{Sin} \alpha \mathrm{h})=0$

or $A \operatorname{Cos} \alpha h+B \operatorname{Sin} \alpha h=024)$

$\mathrm{Q}=-\mathrm{EI} \alpha^{3} \mathrm{C}$

$\mathrm{Q}_{\mathrm{x}=\mathrm{h}}=0, \therefore \mathrm{EI} \alpha^{3} \mathrm{C}=0$ or $\mathrm{C}=0$

Since $\mathrm{C}=-\mathrm{B}, \therefore \mathrm{B}=0$

Thus, Equation (24) becomes:

$\mathrm{A} \operatorname{Cos} \alpha \mathrm{h}+\mathrm{B} \operatorname{Sin} \alpha \mathrm{h}=0$

Or A Cos $\alpha h=0$

As $\mathrm{A} \neq 0, \therefore \operatorname{Cos} \alpha \mathrm{h}=0$

The smallest root is given by $\alpha \mathrm{h}=\frac{\pi}{2}$

$\therefore \alpha=\frac{\pi}{2 h}$ or $\alpha^{2}=\frac{\pi^{2}}{4 h^{2}}$, But $\alpha^{2}=\frac{\mathrm{P}}{\mathrm{EI}}$

$$
\therefore \mathrm{P}_{\mathrm{cr}}=\mathrm{EI} \frac{\pi^{2}}{4 \mathrm{~h}^{2}}
$$

Where $\mathrm{P}_{c r}$ is the Euler's critical load.

This is the elastic buckling (critical) load for a beamcolumn. For the linearly-tapering beam-column,

$I=I_{x}=\frac{\left(\alpha_{0}+\beta x\right)^{4}}{12 h^{4}}$

$\therefore \mathrm{P}_{\text {cr }}=\frac{\pi^{2} \mathrm{E}}{4 \mathrm{~h}^{2}}\left[\frac{\left(\alpha_{0}+\beta \mathrm{x}\right)^{4}}{12 \mathrm{~h}^{4}}\right]=\frac{\pi^{2} \mathrm{E}\left(\alpha_{0}+\beta \mathrm{x}\right)^{4}}{48 \mathrm{~h}^{6}}$

A beam-column will, if not restrained in any particular place, buckle about an axis with the least value of second moment of area, $[13,17]$.

At the free end, $\mathrm{x}=\mathrm{h}$

$$
\begin{aligned}
& \alpha_{0}+\beta x=B_{0} h+\left(b-B_{0}\right) h=b h \\
& \quad \therefore P_{c r}=\frac{\pi^{2} E}{48 h^{6}}(b h)^{4}=\frac{\pi^{2} E b^{4} h^{4}}{48 h^{6}}=\frac{\pi^{2} b^{4} E}{48 h^{2}}
\end{aligned}
$$

\subsection{Buckling of Self-supporting Lattice Tower}

The stiffness of the cantilever beam-column is given by, [11]:

$$
\mathrm{K}=\frac{3 \mathrm{EI}}{\mathrm{h}^{3}}
$$

where $h$ is the height of the column

$$
\therefore \frac{\mathrm{EI}}{\mathrm{h}}=\frac{\mathrm{Kh}^{2}}{3}
$$

The Buckling load of the cantilever column is given by Equation (25) as: $\mathrm{P}_{\mathrm{cr}}=\frac{\mathrm{EI}^{2}}{4 \mathrm{~h}^{2}}=\frac{\mathrm{EI}}{\mathrm{h}} \cdot \frac{\mathrm{\pi}^{2}}{4 \mathrm{~h}}$. But $\frac{\mathrm{EI}}{\mathrm{h}}=\frac{\mathrm{Kh}^{2}}{3}$. For the four-legged self-supporting Lattice tower, $[14,15]$ :

$$
\therefore \mathrm{P}_{\mathrm{cr}}=\mathrm{C}\left(\frac{\mathrm{Kh}^{2}}{3}\right)\left(\frac{\pi^{2}}{4 \mathrm{~h}}\right)=\frac{\mathrm{CK} \pi^{2} \mathrm{~h}}{12}
$$

where $\mathrm{C}=0.04008$

\section{RESULTS AND DISCUSSION}

The self-supporting lattice tower in Fig. 6is subjected to a horizontal load $\mathrm{P}_{1}=1000 \mathrm{KN}$ at its free end (Point $\mathrm{U}$ ). The truss is assumed to be pin-jointed. The tower, being self-supporting, is assumed to be rigidly fixed at its base (Points A and B).

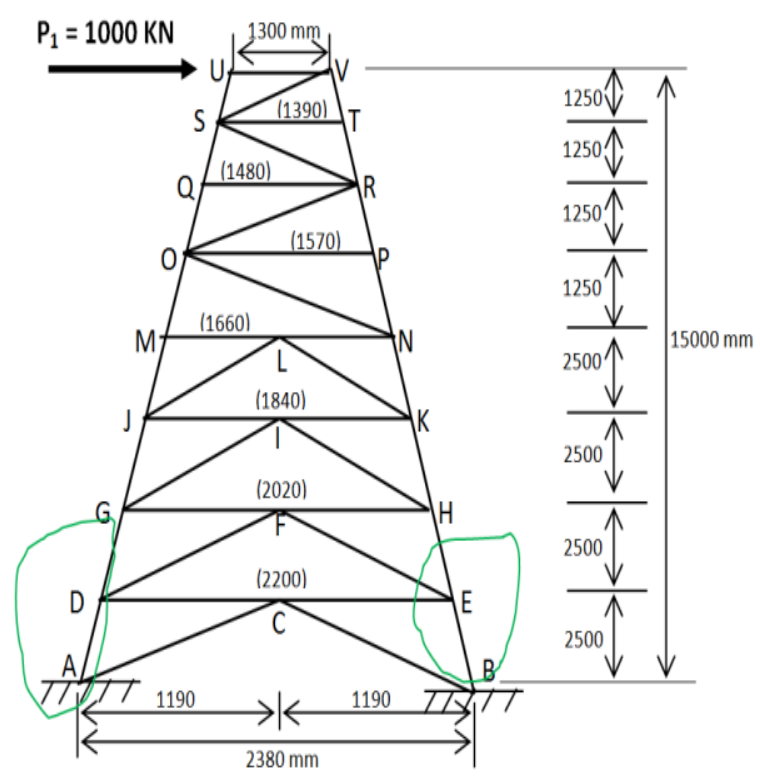

Figure 6: Self-supporting lattice tower under load.

The tower has the following properties:

(i) Density $=7850 \mathrm{~kg} / \mathrm{m}^{3}$

(ii) Young's Modulus, $\mathrm{E}=210 \times 10^{6} \mathrm{KN} / \mathrm{m}^{2}$

Details of the lengths, cross-sectional areas and orientation of the truss members are shown in Table 1.

From Table2,

(i) Deflection at the free end (tip), $(\mathrm{x}=\mathrm{h})=\mathrm{Y}_{1}=$ $0.59133378 \mathrm{~m}$

(ii) Deflection at mid-height, $\left(x=\frac{\mathrm{h}}{2}\right)=\mathrm{Y}_{1 / 2}=$ $0.073638858 \mathrm{~m}$ 
Table 1: Properties of Truss Members

\begin{tabular}{cccccccccc}
\hline S/ & $\begin{array}{c}\text { MEMBE } \\
\mathrm{N}\end{array}$ & $\begin{array}{c}\text { ANGLE } \\
(\text { degrees })\end{array}$ & $\begin{array}{c}\text { LENGTH } \\
(\mathrm{m})\end{array}$ & $\begin{array}{c}\text { CROST- } \\
\text { SECTONAL } \\
\text { AREA } \\
\left(\mathrm{m}^{2}\right)\end{array}$ & S/N & MEMBER & $\begin{array}{c}\text { ANGLE } \\
(\text { Degrees })\end{array}$ & $\begin{array}{c}\text { LENGTH } \\
(\mathrm{m})\end{array}$ & $\begin{array}{c}\text { CROSS- } \\
\text { SECTIONAL } \\
\text { AREA } \\
\left(\mathrm{m}^{2}\right)\end{array}$ \\
\hline 1 & UV & 0 & 1.3 & 0.000225 & 21 & LJ & 249.8 & 2.664 & 0.00512 \\
2 & US & 267.94 & 1.251 & 0.000225 & 22 & LK & 290.2 & 2.664 & 0.00512 \\
3 & VS & 223 & 1.836 & 0.000225 & 23 & Jl & 0 & 0.92 & 0.00512 \\
4 & VT & 272.06 & 1.251 & 0.000225 & 24 & KI & 180 & 0.92 & 0.00512 \\
5 & ST & 0 & 1.39 & 0.000225 & 25 & JG & 267.94 & 2.502 & 0.00512 \\
6 & SR & 319 & 1.903 & 0.000744 & 26 & KH & 272.06 & 2.502 & 0.00512 \\
7 & TR & 272.06 & 1.251 & 0.000744 & 27 & IG & 248 & 2.696 & 0.00512 \\
8 & SQ & 267.94 & 1.251 & 0.000744 & 28 & IH & 292 & 2.696 & 0.00512 \\
9 & QR & 0 & 1.48 & 0.000744 & 29 & GF & 0 & 1.01 & 0.00512 \\
10 & QO & 267.94 & 1.251 & 0.000744 & 30 & HF & 180 & 1.01 & 0.00512 \\
11 & RO & 230.66 & 1.972 & 0.00151 & 31 & GD & 267.94 & 2.502 & 0.00808 \\
12 & RP & 272.06 & 1.251 & 0.0028 & 32 & HE & 272.06 & 2.502 & 0.00808 \\
13 & OP & 180 & 1.57 & 0.0028 & 33 & FD & 246.25 & 2.731 & 0.00512 \\
14 & ON & 322.26 & 2.042 & 0.0028 & 34 & FE & 293.75 & 2.731 & 0.00512 \\
15 & PN & 272.06 & 1.251 & 0.0028 & 35 & DC & 0 & 1.1 & 0.00512 \\
16 & OM & 267.94 & 1.251 & 0.00512 & 36 & EC & 180 & 1.1 & 0.00512 \\
17 & ML & 0 & 0.83 & 0.00512 & 37 & DA & 267.94 & 2.502 & 0.00808 \\
18 & NL & 180 & 0.83 & 0.00512 & 38 & EB & 272.06 & 2.502 & 0.00808 \\
19 & MJ & 267.94 & 2.502 & 0.00512 & 39 & CA & 244.55 & 2.769 & 0.00512 \\
20 & NK & 272.06 & 2.502 & 0.00512 & 40 & CB & 295.45 & 2.769 & 0.00512 \\
\hline
\end{tabular}

From Equation (13), $\mathrm{c}=\frac{4 \mathrm{~h}^{3} \mathrm{P}}{\mathrm{E}}=0.0643 \mathrm{~m}^{5}$

From Equations (15),

$$
\begin{aligned}
\alpha_{1}=0.0152, \alpha_{2}= & -0.0382, \alpha_{3}=-0.003797, \alpha_{4} \\
& =0.004578
\end{aligned}
$$

Therefore Equation (14) becomes:

$0.0152 \mathrm{~B}_{0}{ }^{12}-0.0382 \mathrm{~B}_{0}{ }^{8}-0.003797 \mathrm{~B}_{0}{ }^{4}+0.004578=0$

Using Newton-Raphson method,

$\mathrm{B}_{0}=0.750852 \mathrm{~m}$

Substituting in Equation (12), $\mathrm{b}=\frac{\mathrm{C}}{\mathrm{Y}_{1} \mathrm{~B}_{0}{ }^{3}}=0.2569 \mathrm{~m}$

Table 2 gives the results of the deflection analysis of the self-supporting lattice tower.

Table 2 - Deflection Values for Self-supporting Lattice Tower

\begin{tabular}{cccl}
\hline S/N & Joint & Height from base $(\mathrm{m})$ & Deflection $(\mathrm{m})$ \\
\hline 1 & $\mathrm{U}$ & 15.00 & 0.59133378 \\
2 & $\mathrm{~S}$ & 13.75 & 0.390101219 \\
3 & $\mathrm{Q}$ & 12.50 & 0.292947928 \\
4 & $\mathrm{O}$ & 11.25 & 0.19851868 \\
5 & $\mathrm{M}$ & 10.00 & 0.146828164 \\
6 & $\mathrm{~J}$ & 7.50 & 0.073638858 \\
7 & $\mathrm{G}$ & 5.00 & 0.029030528 \\
8 & $\mathrm{D}$ & 2.50 & 0.004289548 \\
9 & $\mathrm{~A}$ & 0.00 & 0.00 \\
\hline
\end{tabular}

\section{a) Critical Buckling Load of the Equivalent Beam}

The critical buckling load of the equivalent beam is given by Equation (26). So Pcr $=835.89 \mathrm{kN}$

b) Critical Buckling Load of the Lattice Tower
From Table 2,

The deflection of the free end, $\Delta_{\mathrm{u}}=0.59133378 \mathrm{~m}$

Force applied at the free end, $\mathrm{F}_{\mathrm{u}}=1000 \mathrm{KN}$

Hence, stiffness of the structure, $\mathrm{K}=\frac{\mathrm{F}_{\mathrm{u}}}{\Delta_{\mathrm{u}}}=1691.092296$

$\mathrm{KN} / \mathrm{m}$

For the linearly-tapering cantilever tower structure, the critical buckling load is given by Equation (29) where $\mathrm{C}=0.04008$ so $\mathrm{Pcr}=836.19 \mathrm{kN}$. The summary of the results is presented in Table 3. The pin-jointed self-supporting lattice tower shown in Fig. 6 was analysed using both the proposed model and conventional method. The tower is made of steel with Young's Modulus of elasticity $=210 \times 10^{6} \mathrm{KN} / \mathrm{m}^{2}$ and density $=7850 \mathrm{~kg} / \mathrm{m}^{3}$. The tower, being selfsupporting, is assumed to be rigidly fixed at its base. The properties of the tower are given in Table 1.

The results of the deflection analysis of the given lattice tower are displayed in Table 2.The deflection values of the tower are used to obtain the unknown dimensions (b and $\mathrm{B}_{0}$ ) of the model structure, which are in turn deployed in the formulation of the model expression for the computation of the critical buckling load (i.e Equation 26).

The comparison inTable 3 shows a very close agreement between the model result and that obtained using conventional method. The percentage difference of $0.036 \%$ implies that the model result is acceptable. It is also pertinent to note that the proposed model resulted in a lower value of the critical buckling load. 
Table 3 - Comparison of Results

\begin{tabular}{llll}
\hline Description & Lattice Tower & Equivalent beam-column & \% Difference \\
\hline Top dimension & $1300 \mathrm{~mm}$ & $256.90 \mathrm{~mm}$ & \\
Base dimension & $2380 \mathrm{~mm}$ & $750.852 \mathrm{~mm}$ & \\
Critical Buckling Load & $836.19 \mathrm{KN}$ & $835.89 \mathrm{KN}$ & 0.036 \\
\hline
\end{tabular}

\section{CONCLUSIONS}

An expression for the computation of the critical buckling load of self-supporting lattice towers, based on a proposed equivalent solid beam model, was derived in this work, $\left(P_{c r}=\frac{\pi^{2} b^{4} E}{48 h^{2}}\right)$ where $b$ is a dimension of the equivalent beam and $h$ is the height of the lattice tower). The equivalent beam was analysed as a cantilever structure subjected to the same load as the actual self-supporting lattice tower. A comparison of the critical buckling load values of the actual lattice tower and the proposed model shows a marginal percentage difference of $0.036 \%$, which is acceptable. As can be observed from Table 3, the proposed model also gives a lower-bound value of the critical buckling load. This is a welcome safeguard against failure by buckling, since it is obviously safer to use the lower value of the critical buckling load as the basis of structural design. The derived model expressions can also be easily modified to analyze towers of different cross-sectional shapes, such as circular and triangularshaped towers.

\section{REFERENCES}

[1] Agarwal, S. K., "Wind effect on Structures", Allied Publishers Ltd, 1997.

[2] AbdulMuttalib, I. S. "Analysis and Optimum Design of Self-supporting Steel Communication Tower", Journal of Engineering, Volume 19, No. 12, pp. 1673 - 1687, 2013.

[3] Khedr, M. A. and McClure, G. "A Simplified Method for Seismic Analysis of Lattice Telecommunication Towers", Canadian Journal of Civil Engineering, Vol. 27, No. 3, pp. 533 - 542, 2000.

[4] Jones, R.M. "Buckling of Bars, Plates and Shells", CRC., 2007.

[5] Thompson, J. M. T., Hunt, G.W. "A General Theory of Elastic Stability", Wiley., 1973

[6] Zaccaria, D., Bigoni, D., Noselli, G., Misseroni, D. "Structures Buckling Under Tensile Dead Load", Proceedings of the Royal Society A., Vol. 467, 2011.
[7] Bansal, R. K. "Analysis of Uniformly-tapering Rectangular Bar", A textbook of Strength of Materials, $4^{\text {th }}$ Edition, Laxmi Publications Ltd, India, ESM: 0598-535, 2010.

[8] Ghodrati, A. G. and Mossah, S. R. "Seismic Response of 4-legged Self-supporting Telecommunication Towers", International Journal of Engineering. Transactions B: Applications Volume 20, No. 2, 2007.

[9] Kang W., Albermani F., Kitipornchai S. and Lam H. "Modelling and Analysis of Lattice Towers With More Accurate Models", Advanced Steel Construction, Vol. 3, No. 2 2007..

[10] Mohammadi, S. and Hassanirad, A. "Applied and Theoretical Cantilever Beam Free-Vibration Analysis", World Academy of Science, Engineering and Technology, Vol. 61, 2012.

[11] Bhatt, B. and Nelson, H.M.: “Marshall \& Nelson's Structures", Longman Singapore Publishers, 1994.

[12] Jithesh, R. and Vijaya S. "Analysis of Telecommunication Tower Subjected to Seismic and Wind Loading", International Journal of Advancement in Engineering Technology, Management and Applied Sciences, Vol. 1, Issue 2, pp. $67-69,2014$

[13] Jackman, D. E., "Lattice Transmission Tower Analysis", American Society of Engineers. 2002.

[14] Abermani, F. G. A. and Kitipornchai, S. (2003): "Numerical Simulation of Structural Behaviour of Transmission Towers", Thin-Walled Structures, Volume 41, Issues 2-3, ISSN : 0263-8231

[15] Murty, K. S. "Dynamic Response of Lattice Towers and Guyed Masts", American Society of Civil Engineers, 2001.

[16] Osadebe, N.N. and Eze, J.C., "Comparative Study of Vlasov and Euler Instabilities of Axially Compressed Thin-walled Box Columns", Nigerian Journal of Technology, Volume 29, No. 1, 2010

[17] Olanitori, L.M., Afoloayan, J.O. and Arum, C., "Mode of Collapse of Square Single-panel Reinforced Concrete Space-framed Structures with Rigid Beam-Column Joints", Nigerian Journal of Technology, Volume 35, No. 1, 2016 